\title{
Partitioning Vulnerabilities: On the Paradoxes of Participatory Design in the City of Malmö
}

\author{
Erling Björgvinsson and Mahmoud Keshavarz
}

While we are told that the democracies and social fabrics of different societies and communities have become weakened due to the aggression of global capitalism, there is an increasing demand for participation among different actors who share different views but, nonetheless, have a stake in a particular issue. As such, 'participation' has become the buzzword in modern democracies, where equality only seems to be granted through initiating, managing and running different and multiple participatory projects in which it is assumed that underrepresented groups and individuals will be granted a voice.

Among the various participatory and collaborative methodologies and approaches in arts, media and design, the Scandinavian approach to participatory design has become established in academic, non-governmental

E. Björgvinsson

University of Gothenburg, Gothenburg, Sweden

e-mail: erling.bjorgvinsson@gu.se

M. Keshavarz $(\bowtie)$

Uppsala University, Uppsala, Sweden

e-mail: mahmoud.keshavarz@antro.uu.se

(C) The Author(s) 2020

A. M. Dancus et al. (eds.),

Vulnerability in Scandinavian Art and Culture, https://doi.org/10.1007/978-3-030-37382-5_12 
and even governmental sectors in Nordic countries. It is viewed as an approach and method to remedy the assumed lack of participation. This chapter discusses Scandinavian participatory design, its initial aspirations in the 1970s and its paradoxes in the present (2020) when working with local communities in poor European neighbourhoods. The chapter also questions the assumptions held about who is rendered vulnerable and under what conditions; who has fewer resources and is in need of participation and empowerment. We argue that, while the idea of participation is often taken for granted and is equated with democracy, the concept and practice of participation has at no time been neutral. Participation has its own histories, logics and politics, and produces different relations and politics in different contexts, with different actors and different needs. Both the call and the process of participation always takes place in an already partitioned world. As such, participation does not necessarily give equal voices to participants, as is frequently assumed. Rather, it produces new categories of participant, ignores certain other categories and lifts up particular types of participant depending on the power relations involved. ${ }^{1}$

This chapter traces one such instance, when a group of participatory design researchers collaborated with a group of marginalized young music artists from the Swedish suburb of Rosengard. Rosengard, the population of which mainly comprises first- and second-generation migrants, is located in Malmö, the third biggest city in Sweden. Malmö has a population of $340,000,30 \%$ of whom were born outside of Sweden. Erling Björgvinsson was one of the main design researchers behind the project; therefore, this chapter aims to reflect and problematize the project retrospectively. In this chapter, the authors, reflect on how the assumption about the vulnerabilities of a certain group made the call to participation an imperative from the design researchers' perspective. Furthermore, they explain how that assumption continued throughout the process, despite the fact that the group assumed to be vulnerable was actively pushing back against that assumption. This, however, was ignored, as the image of who is vulnerable and in need of empowerment was so strong that it formed the basis of the participatory design project from its very inception. We conclude that participatory methods do not necessarily overcome or resist vulnerabilities that arise due to unequal development but, rather, generate other forms of vulnerabilities that cannot be recognized by employing the same framework used to locate the vulnerability to be overcome with participation. To counter this paradox, we propose part-taking as a working concept that is mindful of the active processes of taking, giving, sharing or 
separating parts - in other words, processes of partitioning vulnerabilities, unfolding through different power relations involved in any participatory setting.

\section{Scandinavian Participatory Design: Aspirations to Side with the VulNerable}

The current dominant participatory design approach within academic design environments has its origins in what is known as Scandinavian Participatory Design. This approach to participatory design has its roots in 'post-war political movements striving for industrial democracy including forms of co-determination by unions and "shopfloor" workers in decision making and efforts to improve the quality of working life, in the broad context of democratization of society' (Gregory 2003, p. 64). As such, Scandinavian participatory design was clearly a political positioning that emphasized siding with vulnerable individuals and groups who should have a say in the process and outcome of the designs that affect them. This position became quite strong in relation to the commercial and industrial designs of the time, which assumed the designer as the expert and sole knower of 'good design'. Since its beginnings in the late 1970s, when it was focused on design for workplaces in relation to their transformation given the advent of computer technology, Scandinavian participatory design (Bjerknes et al. 1987; Bødker 1996) has been guided by two sets of values. These two sets of values have subsequently become its leitmotifs. The first value leitmotif was that those affected by a design should shape the outcome of it; the second was that the role of participatory designer was to side with those who were termed 'resource-weak participants'. This was clearly seen as democratizing design and innovation (Ehn and Kyng 1987) by means of decentring the role of designers-unlike the situation with regard to commercial design processes. This was reflected in the acknowledgement of designing as a collaborative endeavour that emphasized attending to the needs and interests of the underrepresented groups and individuals, who should be part of the process of designing. This aimed not only to address the needs and interests of users, but also to inform and challenge the structures and systems shaping workplaces.

To pay attention to the importance of involving all relevant participants in the process of designing also meant acknowledging the importance of tacit knowledge. This was addressed particularly in the case of design for workplaces by developing ways of designing where the tacit aspects 
of workers' knowledge connected to specific work tasks could be envisioned, articulated and tried out. This was realized by the designers and the participants tried out future work practices with the aid of various prototypes constructed out of paper and cardboard (Ehn and Kyng 1991). The underpinning critique posed by participatory design was focused on a rational view of work where work and competence could be formally and explicitly planned and described. This was a prevalent perspective in the late 1970s and early 1980s with regard to computer science, interaction design and organizational studies (Suchman 1987). The acknowledgement of tacit knowledge thus understood the work as a socially organized and situated activity and, in doing so, emphasized the politics of representation as material transformation.

The underlying convictions in participatory design were that embodied and tacit 'language' of workers was not 'heard', and that they could not speak for themselves on how their work practice could be transformed. For these reasons, the importance of taking the part of the socalled 'resource-weak' participants was emphasized, which in most cases was realized through the involvement of local trade union representatives. As well as enacting specific future work tasks, participatory design also engaged in setting up debates on broader organizational workplace issues. This was undertaken by putting conflictual perspectives on the table through design games that resembled strategy board games. Such joint decision making processes focused on more traditional representational politics.

Although early participatory design stressed the importance of the mutual learning of designers and participants, and siding with the resource-weak participants, in practice, the forms of participationincluding the materials provided, and the settings and the representation-tended to be framed by the designers. For instance, what forms of learning and by who they were envisioned and enacted, can be a subject for debate. One can question whether the designers' learning included what Spivak (1993) calls 'learning to learn how to listen'. The discrepancy in learning between those who initiate participation (designers) and those called into participation (workers and their representatives) was acknowledged to some degree, which led to incorporating ethnography and ethnomethodological studies into participatory design processes. However, this still meant that resource-weak participants, although perhaps not voiceless subaltern subjects, were seen to be in need of being 
amplified and empowered through the abilities of designers and ethnographers. What also was taken for granted was the positions of different participating subjects as fixed within the existing institutional structures. As such, the main focus was on the material transformation of work, rather than the redistribution of power between workers, designers and employers. What drove participatory designing forward was the acknowledgement that everyone participates from their position as recognized by the need to participate: the worker expresses their need as a worker; the designer shares their skills as a designer; the employer participates as an employer. The essentialization of roles and identities framed by the participatory intervention generated unified subjects and homogenous groups, and thus ignored the differences, internal conflicts and power relations within each group of participants.

While participatory design has changed since the late 1970s, nonetheless some of its foundational assumptions and paradoxes have remained. Assumptions such as that workers could not speak for themselves and needed help to articulate a language, achieved through design, for the communication of their needs and desires; or that being a worker was an essentialized condition that made one vulnerable in relation to the transformation of the workplace, thus producing a homogenous group called 'workers'. However, some of these assumptions will be challenged in this chapter as we follow the trajectory of participatory design, from its engagement with the trade union representatives of the 1970s to dealing with civic organizations and self-organized communities in the poor neighbourhoods of European cities inhabited by the working-class migrant population.

As participatory design expanded, so did its deployment in other contexts than Nordic workplace democracy supported by trade unions. Subsequently, participatory design-also known as 'co-design' and, more recently, 'social innovation'-became entangled with 'design thinking' and 'design management' in commercial and entrepreneurial sectors tackling social, environmental and economic issues. Participatory design gradually became a method, rather than a process, in any context and form of designing used merely to extract the 'user' needs required to deliver and sell the best fitted 'solution' to a concrete problem (see Sanders and Stappers 2008).

Since the early 2000s, participatory design researchers have explored how they can engage in reforming issues in various public spheres by linking public, private and civic actors. Given the diversity of perspectives, 
concerns and interests in any public sphere, such an approach investigates the creation of common spaces, using terms such as 'socio-material assemblies', 'Things' and 'infrastructuring', where differences and conflicts may be negotiated through long-term engagement and multiple productions, rather than one single product (Björgvinsson et al. 2010, 2012a, b). Critical to the commercial transformation of participatory design to extract 'user' needs, participatory design researchers have argued, in line with early participatory design leitmotifs, for democratic bottom-up change processes where particular attention should be given to the resource-weak individuals and communities who are excluded from the existing infrastructure of life and work, and who are deemed more vulnerable. It is in this context that participatory design in public spheres has become progressively more popular in governmental institutional agendas, because 'existing structures and policies have found it impossible to crack some of the most pressing issues of our times' (Murray et al. 2010). However, the ambitious claims made by the call for participation in this new context, in practice, may produce a type of facilitation and engagement that has an ambiguous relationship with new and dispersed forms of governance in neoliberal times. Although against extracting 'user' needs, participatory design researchers and the less vulnerable participants, such as public institutions and entrepreneurs, have not been able to acknowledge fully how they shape the terms of participation (Keshavarz and Mazé 2013) and what they gain from the collaboration since they see their roles as mere facilitators-contributors who apparently do not shape the content and direction of participation. In the next section, we will show why this assumption is wrong and how-in taking a facilitating role in linking public, private and civil actors-participatory design researchers, while initiating participation with the aim of empowerment and overcoming the vulnerabilities of resource-weak individuals and communities do, indeed, generate other forms of vulnerability. This becomes possible only through negating how the assumed vulnerable condition is already an active and generative position.

\section{Parting Participants by Participation}

We will now turn to a case where participatory design was deployed to connect a music organization from Rosengård in Malmö to a media company and national actors such as the Swedish public service radio Sveriges Radio and the TV station Sveriges Television. The project was carried 
through Malmö Living Labs for co-production, social innovation and new media, based at Malmö University, which was a research environment that engaged in creating common spaces where private, public and civic actors, amongst other could collaborate together in relation to cultural production. Erling Björgvinsson was part of this Lab, which ran between 2007 and 2012, and was funded, first, by Vinnova (a Swedish government agency that administers state funding for research and development) and, later, by the EU structural fund. ${ }^{2}$

The case study focuses on how the strong participants—such as the researchers and the media company-despite framing the participatory engagement as a bottom-up participation of a democratic nature, owned the process, the terms of participation, the framing of the issue, and the way knowledge was acquired, materially transformed and represented. The needs for the more vulnerable participants were, thus, defined and determined by what the project owners perceived they could offer; the part they could give to the resource-weak participants. Furthermore, the case study focuses on how participation has increasingly become more obsessed with participatory models and methods-in particular, those that generate connections and links between what are seen as diverging social spheres, rather than outcomes. Finally, the case study will show how this leads to partitioning the various vulnerabilities involved.

The collaboration was based on working with a music grassroots organization that, in its own words, worked for multi-ethnic encounters and societal inclusion through cultural activities-partly to counter negative images of migrants as projected by mass media. The members of the music organization were youth music artists, dancers and journalists who were the children or grandchildren of migrants who mainly lived in Rosengard. More powerful actors collaborating directly with the music organization were a medium-sized media company, Malmö Living Labs researchers and, indirectly, Sveriges Television and Sveriges Radio. The collaboration, one of many the researchers conducted with the music grassroots organization, focused on exploring grassroots mobile media broadcast production in connection with Musikhjälpen in 2008; this is a live music show that appeals for money each year to support a specific humanitarian cause. It is set up in a public square and takes place in a different city each year. Three radio or television personalities are locked inside a glass house installed in a public square for six days, and they broadcast live on Sveriges Radio and Sveriges Television. Viewers and listeners send 
text messages requesting a particular song, each request costing a certain amount of money and thereby raising funds.

The medium-sized company was appointed to run the event. They won the bid as Sveriges Radio and Sveriges Television considered they had the best proposals for drawing people to the location of the event, as well as how to make the grassroot initiatives in Malmö visible through the mobile media production facilities that the music grassroots organization had available.

The Lab and its researchers departed from the idea that new media activities cut across private, public and civic spheres in relation to law, policy making and funding that shape who can engage in cultural productions and determine their form and content. Journalism, film, literature and music each comprise numerous complex public spheres that cut across public and private spheres due to how they are regulated and funded (Foucault 1973, 1977; Barry 2001). The Lab work was based on an aesthetic-political perspective that favoured ways of working where 'marginalized' cultural producers, such as young music artists, were brought into partnerships with established strong public and private actors, such as national TV and radio, by means of participatory methods.

One of the issues, prior to the launch of event, related to what each partner received from the collaboration. The media company and one of the researchers in the Lab had the double agenda of promoting both the music organization and its leader because, alongside this collaboration, they were working on selling a television production idea that would be led by the leader of the grassroots music organization. After much debate and disagreement amongst the researchers-which importantly, and paradoxically, did not involve the young members of the music organizationthe Lab and the media company decided to frame the music organization main broadcast webpage as the leader's broadcast channel, with the leader's of the organization's name appearing in the logo, rather than the organization's channel. The grassroots music organization's broadcast thus, primarily, became a vehicle to promote and increase the chance of convincing Sveriges Television to fund the media company and the music organization leader's idea for a programme. This was, in practice, marketdriven lobbyism, rather democratic decision making or an experiment, as claimed by the researchers or imagined by the promises of participatory design.

During the six days of Musikhjälpen, a longstanding conflict in Rosengarrd peaked. The background was that a private owner, Contentus, 
which rented out its premises to numerous non-governmental organizations, and a mosque decided not to prolong the contract and, instead, planned to rent out the premises to Rosengard's district administration and a rental housing company, MKB. This led to the occupation of the premises and ensuing conflicts between the occupants and the police and fire brigade, which was covered extensively in national and international media.

The conflict directly affected the street-journalism collaboration. Due to the mass media coverage of the conflict, suddenly the municipality, which provided the music organization simple premises, felt that music organization had too few activities going on in Rosengård. This was untrue. In fact, the organization engaged many more youngsters in their different activities than the youth activities run by the district administration. Beside this, the district administration had actively worked on recruiting some of the music organization 'leaders'. This consequently created conflict within the organization that, in turn, generated factions among its members. Nevertheless, the district administration pressured the music organization, as they wanted to be able to provide evidence that they had actively engaged in constructive activities in Rosengård from a municipal perspective.

The decisions made by the media company and the researchers in promoting only certain parts of the organization-in particular, its leaderand, in turn, the district administration's pressure on the music organization, exacerbated by mass media, merged into each other to the extent that the organization was torn asunder. What had started out as a democratic engagement had, in practice and undemocratically, favoured certain interests and elements of the participation and oppressed others. While the marginalization of the organization in relation to the public sphere mediated by the big actors was the realization on which the participatory project had embarked, in practice the participation and the process of linking different actors generated new vulnerabilities among the most marginal individuals in the organization. This, however, did not stop those who were badly affected from actively pushing back. A faction of the organization rightly demanded that the specially designed broadcast webpage channel for the event-designed for and based on the identity of one of the leaders-be shut down. The branding, the naming of the Internet domain name, the logo and the structuring of the website had come about through the exclusion of the youngsters from participating in the design and development process. 
The case, although framed as 'giving voice' and empowering the 'marginal' participants through connecting them to normative and powerful actors, was violent and unjust in its realpolitik. It assumed that the organization consisted of unified subjects and homogeneous members, and that one leader could represent the whole organization. Through this assumption, the participation set by design researchers, in truth, tore the music organization apart. The vulnerabilities imagined by participatory design researchers were addressed through a certain type of participation that, eventually, empowered the researchers, the media company and one individual within the organization. This, however, caused a rupture in the social fabric of the organization. While the aspiration to connect all the actors came from the marginalization of young music artists, the participants that benefited nevertheless ignored the vulnerable condition of the young music artists as a productive mode from which they wanted to partake in a different manner.

\section{Disconnecting by Connecting}

While highly situated, the case discussed is not exceptional. This needs to be read in the context of the city of Malmö and its transformation since the turn of the millennium. During the first two decades of the twentieth century in Sweden, the private, public and civic spheres entwined in a distinct way that was highly different from that of the 1970s, when participatory design was taking its initial shape in Nordic countries. The welfare state and workers unions had become significantly weakened, and work precarity and competition increased. Cultural production had now been transformed into creative industries, which emphasized entrepreneurship, innovation and profitability that favoured small-sized new media companies, while it also made cultural work for most more precarious in the form of freelancing. The term 'creative industries' was a product of the Blair government and its establishment of a Creative Industries Task Force in 1997 (Flew 2002, 2011), which influenced Sweden as well. It was a task force aimed at capturing and promoting the enterprise dynamics of cultural producers in the new economy (Cunningham 2002). Closely linked to Blair's venture into creative industries was Charles Leadbeater, who advised the British government on the relationship between the knowledge-driven economy and networked media. While promoting social entrepreneurship, he juxtaposed old and allegedly defunct organizational models found in big companies and universities with the more 
agile, inventive and passionate self-organized professional amateur producers (Leadbeater 1997, 1999; Leadbeater and Miller 2004). He argued that, in order to foster innovative and globally competitive creative practices, what needed to be acknowledged and supported was the value of knowledge capital and social capital; this, in turn, demanded organizational reorientation in the form of creative communities that were based on networks and distributed ownership. McRobbie (2003) critically argued that such idealization of the creative entrepreneur happened at a time when societal structures that supported new creatives were considerably diminished, which lead to increased competition, instability and mobility amongst cultural producers. This is closer to the reality on the ground than that put forth by policy makers and innovation evangelists.

Social and cultural entrepreneurship played a significant role in the 'reinvention' of Malmö, for its transformation from a slumbering harbour city after a period of post-industrial decline. The transformation was heavily influenced by Richard Florida's idea of the importance of the creative class in making cities vital (2002). Dalia Mukhtar-Landgren (2006) points out how the transformation of Malmö-which was centred on supporting knowledge-based entrepreneurial work, building attractive harbour houses, offering vital multicultural city life and cheap services-was heavily policy-driven. Furthermore, she discusses how the policies and political statements related to the transformation in Malmö tend to paint a binary opposition between the green entrepreneurial Western Harbourwhich came to stand for the bright future, and the so-called 'migrant' and 'working-class' districts such as Rosengård, which were described as problematic due to high unemployment and criminality, thereby hampering the city's economic growth. Rather than being discussed as effects of specific and active political and economic processes that transformed and directed Malmö towards segregation, these binaries became taken for granted as truth. On the basis of the 'truth', new social and cultural development and research projects, and efforts to innovate using participatory and collaborative methods were launched to 'activate' and 'empower' those who were left behind in the process of transformation.

Although some of the researchers active in Malmö Living Labs were critical of not only the idea of cultural industries, but also the social and economic redemptive value of the creative class and their entrepreneurship, nonetheless they initially believed in the value of networking across public, private and civic sectors. In particular, they thought it was important to support marginalized civic actors and small cultural producers, 
many of them from Rosengård, in gaining access to larger arenas and powerful partners that were dominating the current public spheres.

In hindsight, Björgvinsson and those working in the Lab were immersed in the ideals that Boltanski and Chiapello (2005) have critiqued as the 'projective city'. A projective city, as a dominant idea governing cities in the 1990s, is a future- and project-oriented city where economic profit and social justice are brought into accord. More precisely, projective has the double meaning of 'project-oriented' and 'projection', as in future-oriented, given that the value of a project is foremost valued in relation to the extent to which it can create new networks, rather than what it achieves in the form of concrete outcomes. In the projective city, the highly valued and employable persons are those who run a multiplicity of transient projects concurrently, and who can link different spheres, given their belief in a distributed creativity and innovation. A particular value is ascribed to those that can multiply connections and proliferate links-not least, the links and connections between unexpected and socially diverging social spheres. Those being linked, however, if they are unable to provide connections, are seen as having little value. The overriding importance ascribed to generating new projects and connections, preferably between diverging social spheres, means that any form of activity can be termed a project. In the projectification of the social life of vulnerable groups, participatory design researchers and stronger cultural workers surmount and blend voluntary work, unpaid and paid work, and stable and unstable ways of making a living, with the hope that this may lead to a new project, another project, yet another projectification. Participatory design researchers as connectionists thus become indifferent to the difference between opposed intentions and values - such as pure commercial, profit-driven endeavours - and civic and social engagement, and what connecting them implies politically, socially and economically. Given that the civic organizations such as the grassroots music organization were unlikely to provide connections and links to what were deemed valuable partners in the eyes of the bigger actors, while the researchers and other strong actors could do so, meant that as the less vulnerable actors increased their value and status the more vulnerable actors did not. What was thus framed as democratic participation and inclusion was fundamentally proliferating exclusion, marginalization and, furthermore, dependency on the middle-class cultural workers and researchers who provide new connections and projects. This uneven relationship in what parts are taken and by whom they are given is clearly revealed when one locates 
it in the context of the proliferation of collaborative and participatory projects in Rosengard in Malmö, where these projects use terms such as 'innovation', 'democracy' and 'inclusion' in their funding applications.

Malmö is, indeed, an exemplary projective city that engages in projects with socially divergent spheres. As the Sydsvenskan article 'Mycket babbel-lite verkstad' (Mikkelsen 2012) describes, between 2000 and 2011 a total of 345 research and development projects were started in Rosengård alone-none of which brought about improved school results and employment rates. This led Nabila Abdul Fattah (2014) to write an article in ETC on 16 December in which she said: 'Stop making us into laboratory rats. I am tired of experimentally engaged people who exploit the system for their own profit, who can tick off that they have done an asphalt safari and done "good".'

Once specific sites and spaces are rendered as places in need of participation, then design practices, such as participatory design, embark on such narratives and turn these places into something else. They compose material, technological, cultural and social practices into compositions of meanings that can be consumed, exchanged and mediated in favour of specific ideologies and interests. However, as discussed, the participation enacted through such approaches in practice often presents a kind of facilitation, linking and engagement with an ambiguous relationship to new and dispersed forms of governance and entrepreneurship in neoliberal times. That is to say, such projects often produce an economic rationale that keeps them separate from the politics involved in the very same situation, as politics may be understood as an exclusive matter of the state (Kiem 2011). Participation is advocated in so far as it diversifies the types of stakeholder, but does not unsettle the forms of hegemonic orders that sustain the economic interests of the state, markets, entrepreneurs and certain classes. People participate to express their shifting interests and values, and to practice their rights in the social sphere (in the best case), while remaining recognizable by the very attributed vulnerabilities that facilitate the status quo-vulnerabilities that make designers turn their attention to those bodies in the first place, as potential collaborators or participants in a design project. Participation, then, becomes a means of affirming the vulnerabilities that could be used to sustain certain practices of power within the current neoliberal rationale. By producing multiple choices, but only within a given framework, participation adjusts and adapts to power structures for the sake of facilitating participatory potentials, by giving a sense of collaboration without taking into account 
the politics of different and contradictory positions, hierarchies, conflicts, dissents and norms that actually constitute politics.

Conflict and dissensus are, in fact, inherent in the political nature of any participation. Participation is not about reaching all-inclusive agreement in order to move on. Neither is it about composing different elements and bringing different actors together to envision possible futures, choices and alternatives within a given framework and setting. Instead, the example discussed shows that participation is about how taking a part, sharing a part, or acting a part in an already partitioned dynamic environment can point to various unrecognized or less-recognized power relations and vulnerabilities involved in any partitioned space produced by any form of participation. As any such call for participation should always be thought of in relation to how such a call partitions the already existing vulnerabilities into a set of social and economic relations and connections that unequally mobilize certain actors while immobilizing others.

\section{Refusal of the Vulnerable Parts}

There has been much academic publishing around participatory design and social innovation, especially in historically strong welfare states such as those of the Nordic countries and the UK. Much of this scholarship, while it may point to different difficulties and issues at hand, nonetheless affirms the necessity and the positive impact of participatory approaches to different social, economic and environmental issues. However, their impact is not evaluated according to a politics of justice and equality demanded and practised by those individuals deemed vulnerable in the first place. The success of these projects lies in the ability of researchers and designers to generate an academic or commercial narrative of the helplessness and vulnerability of the abstract figure of the migrant, worker, elderly and youth, and thus receive acclaim for providing assistance, facilitation and empowering strategies to the vulnerable. ${ }^{3}$ Consequently, this produces specific human beings that are merely understood to exist in order to be helped and protected. On the other hand, these design interventions help the design community to imagine-as well as to satisfy - themselves in relation to the relevancy of their work for our current urgent conditions of growing inequality and precarity.

What happens in participatory design interventions is that vulnerability becomes an ontological condition of those who are deemed to be in need of support and participation. In such interventions academics, municipal 
actors and cultural workers make the assumption that, without the more powerful actors, the marginals cannot change or affect their conditions on their own. Rather than supporting the autonomy of the marginalized, the participation turns the condition into a binary, making one group a homogenous body in need of support and connection, and the other as those with the resources to connect. In such a process, participatory design researchers disavow their own vulnerability, interest and desires, and project them onto one group as comprising its essential condition. As argued by other scholars, vulnerability 'emerges as part of social relation' (Butler et al. 2016) and, as such, through encounters made possible by initiatives of participation. If vulnerability is to be understood as 'politically produced, unequally distributed through and by a differential operation of power' (Butler et al. 2016), the case of participatory design shows that the attempt to resist or overcome the imagined vulnerability is always already about the strategic re-distribution and partitioning of the different vulnerabilities involved. This strategic redistribution, however, runs the risk of aligning with powerful actors because of economic dependency, the value of connections and networking, neoliberal channelling and breaking of the existing autonomous communities and solidarity networks through picking and harvesting active individuals and boosting their careers.

One should remember that to ask for participation is always a call to ask for certain types of participation. It is a demand to follow duties that have not been followed. Take, for instance, the figuration of nation, often represented and imagined as a sacred whole, a transcendental entity or, in secular terms, a body. In order to feel that one is a member of a body, parliament or gathering, one must remember that one is a part of a body as well. Sara Ahmed (2012), in her discussion on wilfulness, states that wilfulness refers to the part that, through its willing against the will of the whole, has forgotten that it is just a part and nothing more.

In order for parts to become parts, they need to acquire a duty. This duty can be thought of as a life duty, which is to say, it must be willing to preserve the life and happiness of the whole body. This means that parts should be sympathetic to each other in order to remain a part or member. This, in turn, demands a form of obedience. Therefore, if a part is not willing to be only a part, a part that follows its duty as a part, then it threatens to break the whole apart. Ahmed makes this clear when she says: '[a] rebellion is a rebellion of a part'. 
The rebellion or the break in the whole-in the body that calls for certain types of participation-is therefore not to be dismissed as a mere conflict of interest. Rather, it is a wilful rebellion of a part as it performs its opposition to its duties, roles, vulnerabilities and attributions, which would perhaps be perceived as a threat to other parts and the will of the whole, a threat to the smoothness and fluidity of participation. To tell the stories of this momentary rebellion, as in the case of a small group of young music artists, is also to disrupt the fluidity and smoothness of participation presented by its advocates, academics and governmental actors alike.

To recognize the differentiated vulnerabilities and the process of its partitioning, we propose the term 'part-taking' (Keshavarz 2016). Parttaking is not flat. It reminds us that a part is, and can be, by its condition, separable from the action that makes it identical to part-taking as whole. As with the story of the grassroots music organization and its younger members, part-taking reminds us that there are other forms, such as partsharing and part-acting, that are simultaneously involved in shared situations.

Thinking about taking a part, refusing a part, sharing a part, acting on a part and risking a part is not a matter of reflection on participation but, rather, it is the very essence of participation itself, understood through the concept of part-taking. Part-taking not only makes us aware of the different values, norms, positions, uneven and unequal benefits within any assembly and gathering, any encounters of multiple actors; part-taking can also challenge assumptions on whose vulnerability is the driver and mobilizer of the call to participation. Part-taking can further expose and make accountable those who the vulnerability of others guides them to initiate participatory projects. More importantly, it can develop sensitivities to recognize the resistance and the struggles of those taken to be the most vulnerable beyond the attributed vulnerability, rendering them passive.

\section{Notes}

1. Scholars in different fields have already challenged the concept of participation. See Bishop (2012), for a critique of participatory, community and relational art emerging since the 1990s; see Miessen (2010), for a critical survey of the term used in architectural and urban design projects. Most importantly, Bill Cooke and Uma Kothari (2001) have challenged the 
seductive claims of participation within the context of participatory development projects, and ask participatory practitioners and theorists to reassess their own role in promoting a set of practices that are, at best, naive about questions of power and, at worst, serve systematically to reinforce, rather than overthrow, existing inequalities.

2. What actors and groups can acquire governmental funding is of particular relevance because research funding is one of many infrastructural devices for the distribution of resources and power. EU structural funds were created to level out differences between regions. It is an example of multilevel organizing of democracy where public and private actors collaborate horizontally across local, regional, national and European levels to promote their interests. This is an organizational form that is not particularly transparent, open, or public, and that is heavily driven by lobbyism. It is an organizational form that, according to some, is a new form of democratic decision making, while others argue that semi-transparent lobbyism is antidemocratic (Erlingsson 1999). The Malmö Living Labs is an example of the later. The larger project, which was headed by Moving Media Southern Sweden, received 25 million kroner, whereof 10 million kroner went to Malmö University and the rest to Malmö Incubator and Moving Media City.

3. Like many other participatory design projects, the narrative published around the case, discussed by the researchers and media company involved, was also that of success. Erling Björgvinsson, however, has critically reflected on the project in another context (see Björgvinsson 2014).

\section{REFERENCES}

Abdul Fattah, N. (2014, December 16). Sluta göra oss i förorten till labbråttor. ETC. http://www.etc.se/ledare/sluta-gora-oss-i-fororten-tilllabbrattor. Accessed 23 February 2017.

Ahmed, S. (2012). A willfulness archive. Theory \& Event, 15(3). https://muse. jhu.edu/. Accessed 19 September 2012.

Barry, A. (2001). Political Machines: Governing a Technological Society. London: Athlone.

Bishop, C. (2012). Artificial Hells: Participatory Art and the Politics of Spectatorship. London: Verso.

Bjerknes, G., Ehn, P., \& Kyng, M. (1987). Computers and Democracy: A Scandinavian Challenge. Aldershot: Gower Publishing.

Björgvinsson, E. (2014). Collaborative design and grassroots journalism: Public controversies and controversial publics. In P. Ehn, E. M. Nilsson, \& R. Topgaard (Eds.), Making Futures: Marginal Notes on Innovation, Design, and Democracy (pp. 227-255). Cambridge, MA: MIT Press. 
Björgvinsson, E., Ehn, P., \& Hillgren, P.-A. (2010). Participatory design and democratizing innovation. In Proceedings of the 11th Biennial Participatory Design Conference (29 November-3 December). Sydney, Australia.

Björgvinsson, E., Ehn, P., \& Hillgren, P.-A. (2012a). Design things and design thinking: Contemporary participatory design challenges. Design Issues, 28(3), 101-116.

Björgvinsson, E., Ehn, P., \& Hillgren, P.-A. (2012b). Agonistic participatory design working with marginalized social movements. CoDesign: International Journal of CoCreation in Design and the Arts, 8(2-3), 127-144.

Bødker, S. (1996). Creating conditions for participation: Conflicts and resources in systems development. Human-Computer Interaction, 11(3), 215-236.

Boltanski, L., \& Chiapello, E. (2005). The Spirit of New Capitalism. London: Verso.

Butler, J., Gambetti, Z., \& Sabsay, L. (Eds.). (2016). Vulnerability in Resistance. Durham: Duke University Press.

Cooke, B., \& Kothari, U. (Eds.). (2001). Participation: The New Tyranny? London: Zed Books.

Cunningham, S. (2002). From cultural to creative industries: Theory, industry and policy implications. Media International Australia Incorporating Culture and Policy, 102(1), 54-65.

Ehn, P., \& Kyng, M. (1987). The collective resource approach to systems design. In P. Ehn \& M. Kyng (Eds.), Computers and Democracy-A Scandinavian Challenge (pp. 17-58). Aldershot, UK: Avebury.

Ehn, P., \& Kyng, M. (1991). Cardboard computers: Mocking-It-Up or hands-on the future. In J. Greenbaum \& M. Kyng (Eds.), Design at Work: Cooperative Design of Computer Systems. Hillsdale, NJ: Lawrence Erlbaum Associates.

Erlingsson, G. Ó. (1999). Ekonomi, demokrati och identitet $i$ ett Europa under omvandling. En analys av ett forskningsomraide. Lund: Department of Political Science, Lunds Universitet.

Flew, T. (2002). Beyond ad hocery: Defining creative industries. Paper presented at Second International Conference on Cultural Policy Research, Wellington, New Zealand.

Flew, T. (2011). Origins of creative industries policy. In T. Flew (Ed.), The Creative Industries: Culture and Policy. London: Sage.

Florida, R. (2002). The Rise of the Creative Class. New York: Basic Books.

Foucault, M. (1973). The Birth of the Clinic. London: Tavistock.

Foucault, M. (1977). Discipline and Punish: The Birth of the Prison. London: Penguin.

Gregory, J. (2003). Scandinavian approaches to participatory design. International Journal of Engineering Education, 19(1), 62-74.

Keshavarz, M. (2016). Design-Politics: An Inquiry to Passports, Camps, and Borders (PhD dissertation). Malmö: Malmö University. 
Keshavarz, M., \& Mazé, R. (2013). Design and dissensus: Framing and staging participation in design research. Design Philosophy Papers, 11(1), 7-29.

Kiem, M. (2011). Designing the social, and the politics of social innovation. Design Philosophy Papers, 9(3), 207-216.

Leadbeater, C. (1997). The Rise of the Social Entrepreneur. London: Demos.

Leadbeater, C. (1999). Living on Thin Air: The New Economy. London: Penguin.

Leadbeater, C., \& Miller, P. (2004). The Pro-Am Revolution: How Enthusiasts Are Changing Our Economy and Society. London: Demos.

McRobbie, A. (2003). 'Everyone is creative': Artists as pioneers of the new economy? Zürich: Museum für Gestaltung. http://www.k3000.ch/becreative/ texts/text_5.html. Accessed 2 July 2019.

Miessen, M. (2010). The Nightmare of Participation. Berlin: Sternberg Press.

Mikkelsen, J. (2012, April 5). Mycket babbel-lite verkstad. Sydsvenskan. http:// www.sydsvenskan.se/. Accessed 23 February 2017.

Mukhtar-Landgren, D. (2006). Den delade staden-Välfärd för alla i kunskapsstaden Malmö. Fronesis, 18, 120-132.

Murray, R., Caulier-Grice, J., \& Mulgan, G. (2010). The Open Book of Social Innovation. London: The Young Foundation.

Sanders, E. B.-N., \& Stappers, P. J. (2008). Co-creation and the new landscapes of design. CoDesign, 4(1), 5-18.

Spivak, G. C. (1993). Can the subaltern speak? In L. Chrisman \& P. Williams (Eds.), Colonial Discourse and Post-Colonial Theory: A Reader. New York: Harvester Wheatsheaf.

Suchman, L. (1987). Plans and Situated Actions: The Problem of Human Machine Communication. Cambridge, UK, and New York: Cambridge University Press. 
Open Access This chapter is licensed under the terms of the Creative Commons Attribution 4.0 International License (http://creativecommons.org/licenses/ by $/ 4.0 /$ ), which permits use, sharing, adaptation, distribution and reproduction in any medium or format, as long as you give appropriate credit to the original author(s) and the source, provide a link to the Creative Commons license and indicate if changes were made.

The images or other third party material in this chapter are included in the chapter's Creative Commons license, unless indicated otherwise in a credit line to the material. If material is not included in the chapter's Creative Commons license and your intended use is not permitted by statutory regulation or exceeds the permitted use, you will need to obtain permission directly from the copyright holder.

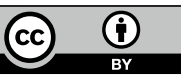

